\title{
Renal Cell Carcinoma: \\ Biological Features and Rationale for Molecular-targeted Therapy
}

\author{
Mototsugu Oya \\ Department of Urology, Keio University School of Medicine, Tokyo, Japan
}

(Received for publication on April 16, 2008)

(Accepted for publication on July 17, 2008)

\begin{abstract}
Cancer cells are characterized by indefinite proliferation, invasiveness and metastases. These characteristics are usually related to one another. Namely, cancer cells that proliferate rapidly tend to invade and metastasize. Renal cell carcinoma (RCC) typically does not proliferate rapidly nor does it invade the surrounding tissues, but it does metastasize. RCC has several peculiar characteristics that are not observed in other cancers: a relatively late recurrence, a high frequency of paraneoplastic syndrome, hypervascularity and the spontaneous regression of metastatic lesions after the excision of the primary tumor. These clinical observations suggest that cytokines or growth factors are important contributors to microenvironments favoring the growth of cancer cells. Thus, the blockade of cell-to-cell communication might have some therapeutic potential. Accordingly, a popular strategy for molecular-targeted therapy for RCC targets the vasculization of RCC induced by vascular endothelial growth factor (VEGF). This review highlights the biological features of RCC that are relevant to molecular-targeted therapy. (Keio J Med 58 (1) : 1-11, March 2009)
\end{abstract}

Keywords: renal cell carcinoma, molecular-targeted therapy, cytokine, vascular endothelial growth factor (VEGF)

\section{Introduction}

With the advent of such imaging modalities as ultrasonography and computed tomography, renal cell carcinomas (RCC) are now frequently detected at an asymptomatic early-stage of carcinogenesis. These carcinomas are usually successfully treated by surgical resection. However, patients with metastatic disease either at presentation or after surgical treatment have a poor prognosis. For these patients, immunotherapy including the administration of interferon (IFN)- $\alpha$ and interleukin (IL)-2 has been the most common treatment option for the past 20 years. Recently, however, novel molecular findings have led to the introduction of molecular-targeted therapy for RCC. RCC is classified pathologically into five types, i.e., clear cell, papillary, chromophobe, collecting duct carcinoma and unclassified. Clear cell RCC accounts for about $80 \%$ of all RCCs and is well known for its hypervascularity. Clinical trials using anti-angiogenic agents proved that these agents were effective for the treatment of RCC. The U.S. Food and Drug Administration (FDA) subsequently approved two anti-angiogenic agents, sorafenib and sunitinib, for the treatment of metastatic RCC. Both of these agents are small-molecule tyrosine kinase inhibitors (TKIs). Temsirolimus, an mTOR (mammalian target of rapamycin) inhibitor, was also recently approved by the FDA. In Japan, the government approved the use of sorafenib in January 2008 and is in the process of approving sunitinib. Thus, the era of molecular-targeted therapy for RCC has now begun.

\section{Peculiar Characteristics of RCC}

Clinicians treating RCC patients sometimes feel that this malignant neoplasm has characteristics that are not observed in other cancers. Hence, patient outcome is sometimes unpredictable: some patients with metastases live longer than 5 years, and late recurrence can occur as long as 5 or even 10 years after the initial surgery. Occasionally, RCC is accompanied by paraneoplastic syn-

Reprint request to: Mototsugu Oya, MD, Department of Urology, Keio University School of Medicine, 35 Shinanomachi, Shinjuku-ku, Tokyo 160-8582, Japan, Tel: +81-3-5363-3824, Fax: +81-3-3225-1985, E-mail: moto-oya@sc.itc.keio.ac.jp 


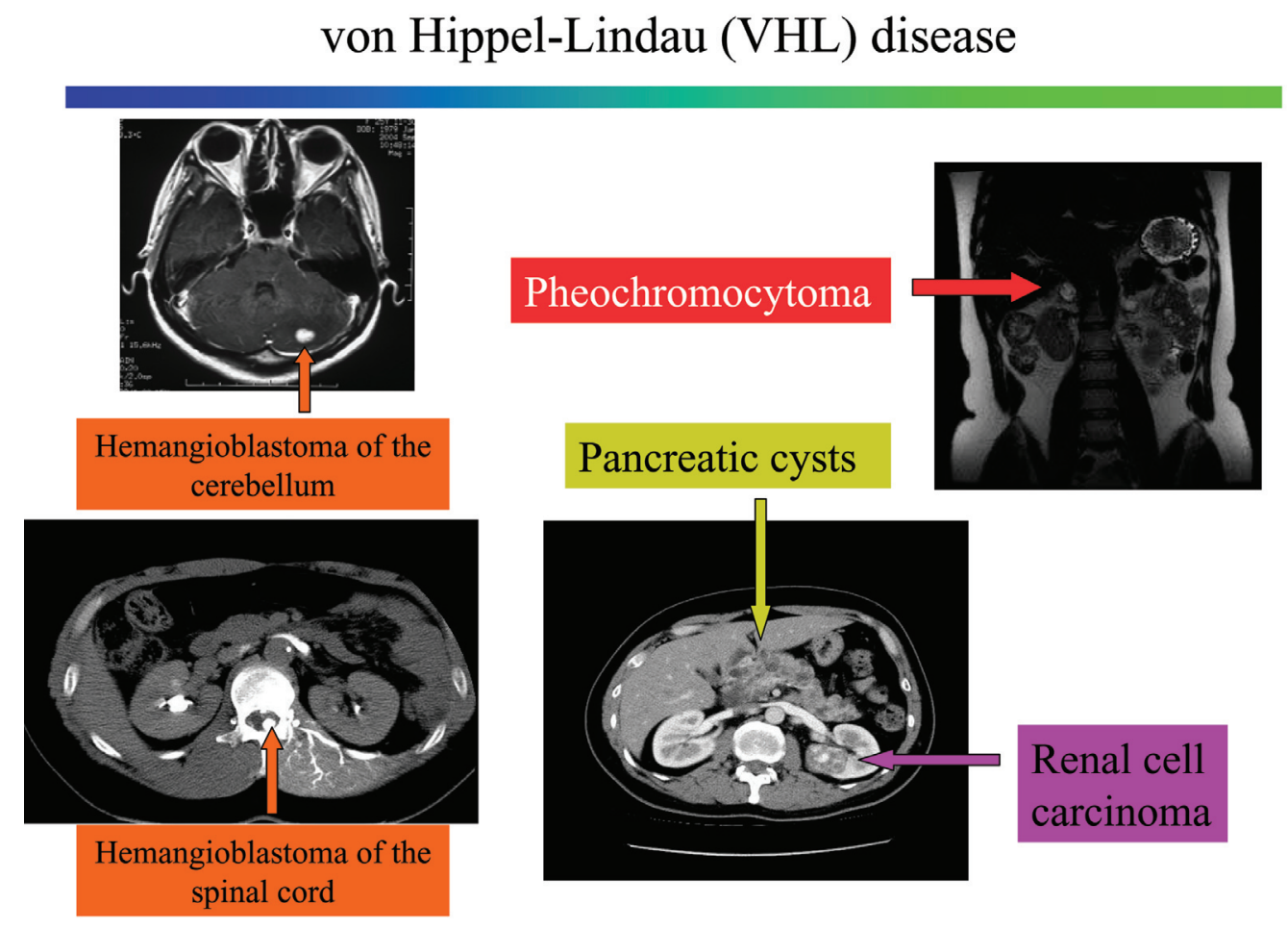

Fig. 1 VHL disease. The solid tumors are all benign tumors with hypervascularity, except for RCC.

drome, with symptoms such as fever, erythrocytosis, leukocytosis and hypercalcemia. This syndrome is caused by the secretion of cytokines or hormones from the tumor. ${ }^{1}$ Growth factors like vascular endothelial growth factor (VEGF) and platelet-derived growth factor (PDGF) are also secreted from RCC, inducing hypervascularity. Although RCC is a solid tumor, immunotherapy (not chemotherapy) has been the standard treatment for metastatic RCC. This tumor type has been regarded as immunogenic because spontaneous regression ${ }^{2}$ has been observed. These characteristics of RCC can appear very peculiar to clinicians.

\section{Pathological Classification}

RCCs comprise a heterogeneous group of tumors. The most recent classification in $2002\left(\right.$ UICC $\left.^{3}\right)$ describes five subtype classifications, i.e., clear cell RCC, papillary RCC, chromophobe RCC, collecting duct carcinomas, and unclassified RCC. This classification reflects the location within the nephron from which the tumors originate. Epithelial cells of the proximal part of the renal tubule give rise to clear cell and papillary RCC, while the collecting tubule of the nephron gives rise to chromophobe RCC and collecting duct carcinomas. At present, these four types of RCC are recognized as distinct entities.

\section{Molecular Pathology of Clear Cell RCC: von Hippel-Lindau (VHL) Tumor Suppressor Gene}

The most important molecular disorder in clear cell RCC involves the VHL tumor suppressor gene. VHL disease is a multiorgan disorder caused by an inherited mutation of the VHL tumor suppressor gene, located on chromosome $3 \mathrm{p} 25$. VHL patients present with hemangioblastomas of the retina, cerebellum, or spinal cord; visceral cysts; and solid tumors. ${ }^{4}$ The solid tumors can include RCC, pheochromocytomas, and pancreatic islet cell tumors (Fig. 1). All these tumors are benign, hypervascular tumors, except for RCC. The development of these disorders is linked to the inactivation of the remaining wild allele in the organ tissue. Therefore, the pathology is explained by Knudson's two-hit theory. VHL mutation or gene silencing by promotor hypermethylation is also observed in sporadic RCC. ${ }^{5,6}$ In summary, the loss of VHL tumor suppressor gene function occurs in both familial and most sporadic cases of clear cell RCC.

The VHL tumor suppressor protein acts as the substrate recognition component of a ubiquitin E3 ligase that targets protein degradation, including HIF- $\alpha$ subunits. $^{7}$ The loss of VHL protein function as a result of gene mutation leads to the constitutive expression of HIF- $\alpha .{ }^{8}$ To date, three HIF- $\alpha$ subunits, HIF- $1 \alpha$, HIF- $2 \alpha$, 


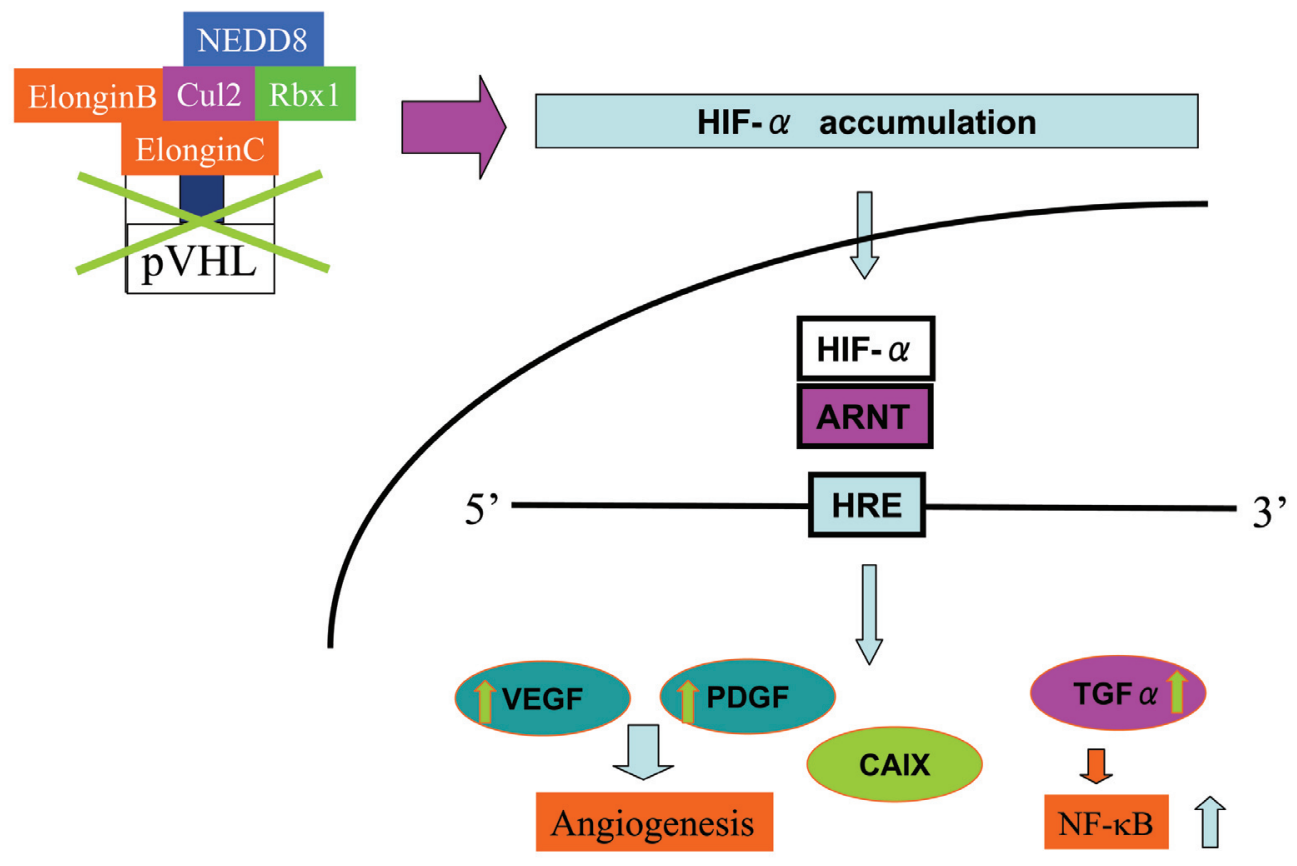

Fig. 2 VHL inactivation leads to HIF- $\alpha$ activation. HIF is a transcription factor that induces several genes related to hypoxia. VEGF, PDGF, TGF- $\alpha$ and CAIX are representative genes induced by HIF. HRE: hypoxia response element ARNT: arylhydrocarbon receptor nuclear translocator

and HIF-3 $\alpha$, have been cloned. HIF- $\alpha$ induces several target genes including VEGF, PDGF, TGF- $\alpha$, carbonic anhydrase IX (CAIX) and Glut-1. ${ }^{9}$ RCC is characterized by prominent neovasculization, probably as a result of the overexpression of VEGF. Several reports have linked angiogenesis and VHL mutation. ${ }^{10,11}$ Angiogenesis is the process during which new blood vessels are formed from preexisting vessels, and this process is necessary for tumors to receive the nutrition and oxygen that they require for growth. Highly proliferative tumors are often exposed to hypoxia, especially at their centers. HIF is physiologically induced in these situations. In contrast, clear cell RCC is highly angiogenic in normoxic conditions as a result of the induction of VEGF arising from the activation of HIF through the inactivation of $\mathrm{pVHL}$ (Fig. 2).

CAIX has been implicated as a marker of RCC because CAIX is expressed in clear cell RCC, but not in normal kidney tissues. CAIX protein is a member of the carbonic anhydrase family and plays a role in the regulation of the cell proliferation involved in hypoxia. Conceivably, this protein may be needed for tumor survival during early carcinogenesis, when the cancers are exposed to hypoxia. Bui et al. reported that CAIX is an independent predictor of longer survival among RCC patients. ${ }^{12}$ However, these results were not validated by a recent report. ${ }^{13}$ Regardless of this lack of validation, the high frequency of positive staining for CAIX in clear cell RCC suggests that this protein could be used as a marker for diagnosis in biopsy samples or as a marker of early carcinogenesis.

The deregulation of the VHL-HIF pathway explains the hypervascularity seen in RCC but not the aberrant proliferation. Kondo et al. showed that tumor suppression by the VHL protein was overridden by an HIF- $2 \alpha$ mutant that escaped recognition by VHL proteins. Introducing this HIF-2 $\alpha$ mutant into cells with wild-type VHL proteins promoted tumor growth. Therefore, HIF-2 $\alpha$ is considered to boost RCC proliferation. ${ }^{14}$ However, the downstream target molecules of HIF- $2 \alpha$ that are involved in RCC carcinogenesis remain to be elucidated. Additional evidence of the crucial role of HIF in RCC tumor growth was presented by Maranchie et al. ${ }^{15}$ They blocked the binding of VHL to HIF in RCC cells re-expressing VHL, restoring tumor growth.

Other functions of the VHL protein include cilia formation. Renal cancer cells that lack pVHL have recently been reported to be deficient in cilia, whereas the ectopic expression of pVHL restored cilia growth. ${ }^{16-18}$ Autosomal dominant polycystic kidney diseases (ADPKD) are caused by mutations in proteins localized in the cilia or centrosomes. ${ }^{19}$ Accordingly, in kidneys with VHL disease, premalignant cysts composed of clear cells are observed. pVHL binds to and stabilizes microtubules. ${ }^{20}$ Therefore, the loss of $\mathrm{pVHL}$ is related to cilia formation. Indeed, in pVHL-deficient cells, the orientation of microtubule growth is disturbed, resulting in disordered microtubule assembly. pVHL binds to microtubules and 
the Par3-Par6-aPKC complex to direct microtubule orientation. ${ }^{21}$ This enables the centrosome to migrate to the apical membrane. The membrane-anchored centrosome forms the basal body of the cilium. These sequential dysfunctions cause the loss of cilia formation. Interestingly, cilia formation is linked to the cell cycle. Differentiated cells in $\mathrm{G}_{0}$ have cilia. In polycystic kidneys, the loss of cilia is strongly related to an increase in the proliferation of cyst-lining epithelial cells. The deregulation of cell cycle control that is linked to ciliary loss may be mediated by the expression of NIMA-related protein kinases that play a role in the G2-M transition as well as in ciliary loss. ${ }^{22,23}$ The loss of cilia followed by the aberrant cell cycle control might be related to the early carcinogenesis of RCC.

\section{RCC as Cytokine-producing Tumor}

RCC was formerly nicknamed 'internist's tumor' because most patients with RCC present with symptoms like fever of unknown origin, hypercalcemia, and/or erythrocytosis and are initially referred to internists for diagnosis. The above-mentioned symptoms are collectively known as paraneoplastic syndrome, as they are produced by the aberrant secretion of cytokines and/or hormones. Aggressive RCC phenotypes are occasionally associated with inflammatory paraneoplastic syndrome, which can be detected as an elevated serum CRP level. Accordingly, an elevated CRP level is associated with a poor prognosis in patients with RCC. ${ }^{24,25}$ IL-6 is also thought to be a major causative cytokine because $50 \%$ or more of patients with metastatic RCC have elevated IL-6 levels, which in turn are correlated with elevated CRP levels. ${ }^{26,27}$ IL-6 is also secreted by cancer cells and may thus play a role in cancer development and may accelerate cancer cell growth in an autocrine or paracrine manner. ${ }^{28}$ Furthermore, IL-6 is an independent prognostic factor of metastatic RCC. ${ }^{29}$

Yoshida et al. investigated the three major inflammatory cytokines, namely, IL- 6 , TNF- $\alpha$, and IL-1 $\beta$. The serum IL-6 level was strongly correlated with the presence of metastasis and a high tumor grade. ${ }^{30}$ They established RCC cell lines for short periods and demonstrated that IL-6 was the only inflammatory cytokine secreted into the supernatants of the cell lines. TNF- $\alpha$ and IL- $1 \beta$ were not detected in the majority of the cell line supernatants, suggesting that these two cytokines are secreted from cells other than RCCs, presumably monocytes or macrophages.

The predominant mechanism by which these cytokines are newly synthesized involves an inducible transcriptional initiation of their respective genes. This phenomenon is governed by transcription factors that bind to the regulatory regions of the genes. Cytokine-inducible transcription factors, including NF- $\kappa$ B, STAT3 and C/EBP- $\beta$
(NF-IL6), might contribute to the deregulated cytokine expression observed in RCC. We previously showed that some RCCs contain activated NF- $\mathrm{KB}$, as determined using an electrophoretic mobility shift assay (EMSA) and immunohistochemistry. ${ }^{31}$ Recent reports have shown that NF- $\kappa \mathrm{B}$ activity is related to pVHL function. ${ }^{32,33}$ Thus, NF- $\kappa \mathrm{B}$ has been recognized as a therapeutic target of RCC. ${ }^{34,35}$ We also showed that STAT3 activation, as determined using immunohistochemistry with a phosphorylated antibody, was associated with metastasis and that STAT3 activation was an independent prognostic factor. ${ }^{36} \mathrm{C} / \mathrm{EBP}-\beta$ is also activated in invasive phenotypes of RCC. ${ }^{37}$ The clonal selection of RCC through the production of these cytokines, which enable autocrine or paracrine growth, may have a growth advantage, thereby contributing to tumor development.

\section{Importance of Cytokines and Growth Factors to RCC Carcinogenesis}

Cancer cells are characterized by indefinite proliferation, invasiveness and metastases. These characteristics are usually related to one another. Namely, cancer cells that proliferate rapidly tend to invade and metastasize. RCC typically does not proliferate rapidly nor does it invade the surrounding tissues, but it does metastasize. Late recurrence is occasionally observed in RCC, and early-stage RCC has recurred as long as 10 years after the initial operation. This means that small, early-stage RCC that had metastasized at the time of the initial operation required 10 years to grow to a clinically identifiable size. Renal cancer cells seem to require the help of surrounding cells or tissues to survive. Therefore, growth factors or cytokines, including VEGF and IL-6, are important for the cancer cells' ability to communicate with surrounding cells. IL-6 works as an autocrine and/or paracrine growth factor. Furthermore, IL-6 might act as a tumor microenvironmental factor that can promote tumor-associated macrophages (TAMs), the most abundant immunosuppressive cells in the tumor microenviroment. $^{38}$

\section{RCC is Immunogenic but Seems to Escape Immuno-surveillance}

$\mathrm{RCC}$ is thought to be immunogenic because spontaneous regression has been documented. Resected RCC specimens show significant T-cell infiltration, suggesting the immunosuppressive activity of $\mathrm{T}$ cells against the tumor. These observations led to the clinical use of immunotherapy, including the administration of IFN- $\alpha$ or IL-2, as the standard therapy for RCC for 20 years, with objective response rates $10-20 \% .{ }^{39}$ Other immunotherapy options include allogenic stem cell transplantation, adoptive T-cell transfer, and vaccination using dendric cells 
or heat shock protein peptide complexes. The major rationale for immunotherapy is the induction of CD8+ cytotoxic T-cells that recognize the tumor antigen and attack the cancer cells. CD4+ cells play a fundamental role in the induction and maintenance of the effector function. However, few clinically relevant tumor-associated antigens have been identified. ${ }^{40}$

The limited success of immunotherapies might be due to an immune escape mechanism in RCC cells. Representative mechanisms include the loss or down-regulation of HLA class I antigens, ${ }^{41}$ the secretion of immunosuppressive cytokines like IL-10, TGF- $\beta$ or VEGF; or the lack of costimulatory factors and the overexpression of inhibitory costimulatory factors.

\section{Modulation of Costimulatory Molecules}

The modulation of costimulatory molecules might enable the efficacy of immunotherapy to be increased. One approach is to boost costimulatory molecules involved in the effective T-cell response. Another approach is to inhibit costimulatory molecules that block the effective T-cell response.

For an effective response, two signals are generally required. The first signal involves the interaction of the T-cell receptor (TCR) and the MHC class I/II peptide complex, whereas the second signal occurs via the costimulatory molecules. The B7 family molecules include B7-1, B7-2 and the B7-H subfamily. Both B7-1 and B7-2 are expressed on antigen-presenting cells (APC) and interact with CD28 (for stimulation) and cytotoxic T-lymphocyte-associated protein 4 (CTLA4; for inhibition). Indeed, a lack of B 7-1 and B7-2 has been reported in $\mathrm{RCC}^{42}$ In contrast, the B7-H subfamily negatively regulates immune responses. The expression of $\mathrm{B} 7-\mathrm{H} 1$ and B7-H4 have been reported in RCC. The interaction of B7-H1 on RCC cells with PD-1 on T-cells has been reported to induce apoptosis in activated T-cells. ${ }^{43}$ Notably, RCCs with B7-H1 expression have been associated with a poor patient outcome. ${ }^{44}$ Furthermore, the expression of PD-1 in the tumor-infiltrating T-cells is also an indicator of a poor patient prognosis. ${ }^{45}$

\section{Role of Tumor Cytokine Microenvironment in Immune Escape}

As described above, RCC secrets various cytokines that might mediate immune escape. Immunosuppressive cytokines like IL-6, IL-10, TGF- $\beta$ or VEGF may act to suppress effector T-cells. Furthermore, cytokines produced by various immune cells (TNF- $\alpha$ and IL-6) may promote tumor growth in the tumor microenvironment. Another mechanism leading to immune escape may be the generation of regulatory $\mathrm{T}$ cells (Tregs) and myeloidderived suppressor cells (MDSCs), which are induced by soluble factors secreted from cancer cells. Tregs (CD4+, CD25+, Foxp3+, IL 7R+) are essential to the homeostasis of the immune system through their negative regulation of CD4+ and CD8+ T cell activation. RCC patients reportedly have elevated levels of Tregs in their blood, compared with the levels in healthy volunteers. During treatment with IL-2, RCC patients with objective responses achieved a decrease in the number and frequency of Tregs, whereas an increase in Tregs was observed in patients with progressive disease. ${ }^{46}$ Thus, the manipulation of Tregs may have therapeutic potential for the treatment of RCC.

The relevance of MDSCs to the impaired immune function arises from the production of arginase, which depletes arginine in the microenvironment, thereby impairing $\mathrm{T}$ cell proliferation. An increase in MDSCs has been observed in RCC patients. ${ }^{47}$ Prostaglandin E2 is produced by cancer cells, inducing arginase expression. The manipulation of MDSCs also has therapeutic potential for the treatment of RCC. The blockade of prostaglandin E2 using non-steroidal anti-inflammatory drugs (NSAIDs) might boost the efficacy of immunotherapy.

\section{Is HIF the Dominant Transcription Factor Inducing VEGF?}

Theoretically, the induction of VEGF by HIF activation is the most important mechanism of hypervascularity in RCC. However, VEGF might also be induced by the activation of other transcription factors. Therefore, we explored whether VEGF is dominantly induced by HIF. We employed an siRNA knockdown method to clarify the functional role of the HIF subunits, namely HIF- $1 \alpha$ and HIF- $2 \alpha$, in VEGF transcription. ${ }^{48}$

We used 9 RCC cell lines. The VHL gene was inactivated in 4 of the 9 cell lines because of either a frame shift mutation or hypermethylation. All four cell lines with VHL gene activation had either a truncated HIF-1 $\alpha$ protein or defective HIF-1 $\alpha$ expression. The reduced protein expression was caused by a low level of mRNA expression. In the cell lines without HIF- $1 \alpha$ expression, VEGF expression was maintained by HIF- $2 \alpha$ expression. Indeed, 769P cells (lacking both HIF-1 $\alpha$ and HIF-2 $\alpha$ ) had a low level of VEGF expression. In these HIF-1 $\alpha$ defective cell lines, the knockdown of the HIF-2 $\alpha$ gene showed that HIF- $2 \alpha$ regulated VEGF production, irrespective of the VHL gene mutation status. In contrast, HIF- $1 \alpha$ played a predominant role in VEGF secretion in the cells expressing both wild-type HIF- $1 \alpha$ and HIF- $2 \alpha$ proteins because HIF-1 $\alpha$ knockdown resulted in marked down-regulation of VEGF secretion. These results suggest that HIF- $\alpha$ is mainly responsible for the induction of VEGF expression and that other mechanisms play a minimal role. 


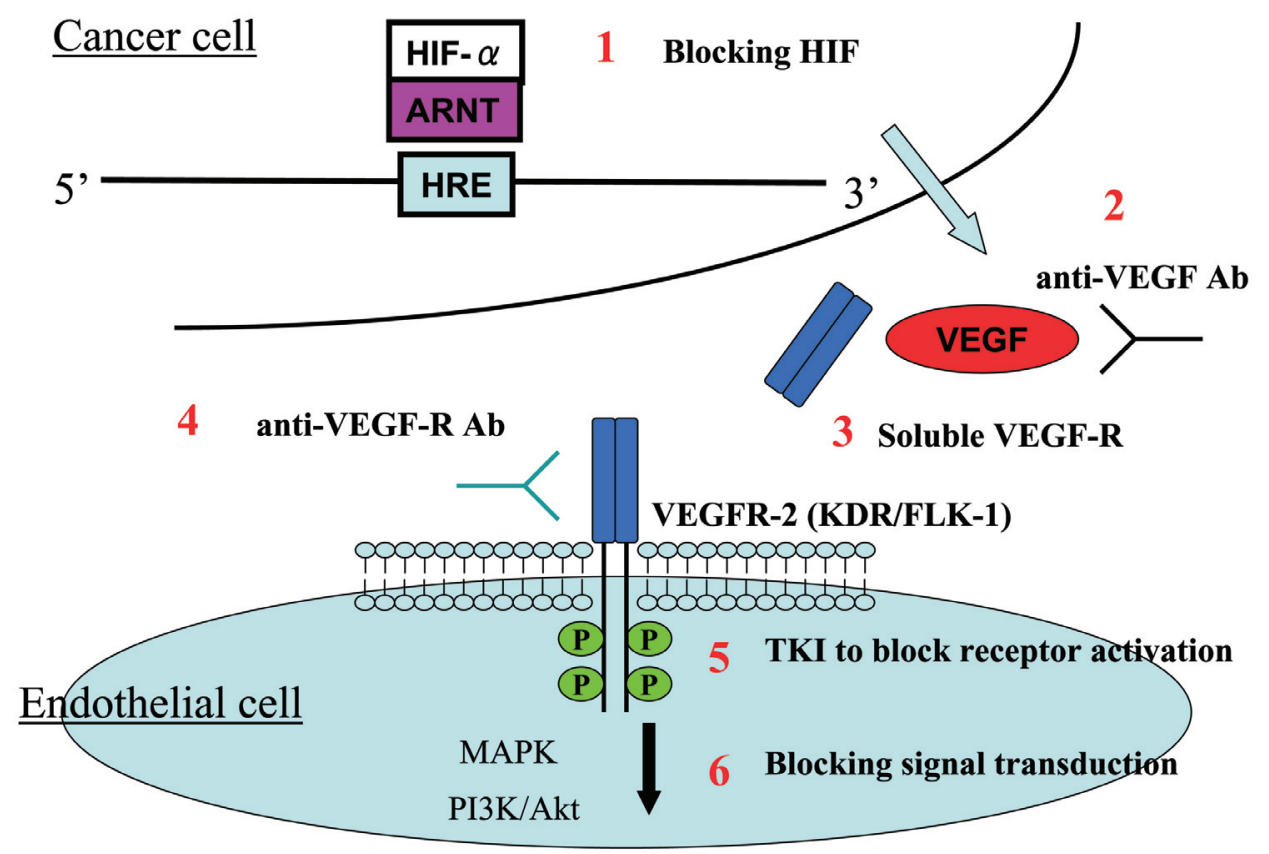

Fig. 3 Six methods for blocking the activity of VEGF. Transcriptional controls, trapping methods, TKI of VEGF-R and signal blockade are possible mechanisms. At present, TKI is the most useful and widely applied clinical modality.

\section{VEGF-targeted Therapy}

HIF-mediated angiogenesis via VEGF induction could theoretically be targeted using six different methods (Fig. 3).

1) Blocking of HIF activation: Two agents, $103 \mathrm{D} 5 \mathrm{R}^{49}$ and NSC $644221,{ }^{50}$ have been reported to block HIF activation. However, the efficacy and safety of these drugs have not yet been evaluated in animal models. An mTOR inhibitor has also been reported to have an indirect suppressive effect on HIF activation. ${ }^{51}$

2) anti-VEGF antibody (Ab), bevacizumab: A placebocontrolled randomized control trial for metastatic RCC patients showed that high-dose bevacizumab prolonged the time to progression, compared with that in the control group. However, no significant differences in overall survival were seen. Minimal toxic effects, like hypertension and asymptomatic proteinuria, were seen. ${ }^{52}$

3) VEGF Trap: VEGF Trap is an engineered soluble receptor made from the extracellular domains of VEGFR1 and VEGFR2. VEGF Trap binds to VEGF with a higher affinity than bevacizumab. The toxicities seen during a phase I trial examining the subcutaneous and intravenous administration of VEGF Trap were hypertension and proteinuria. ${ }^{53}$

4) anti-VEGFR Ab: The blockade of VEGFR-1 activation has been shown to inhibit pathologic angiogenesis and tumor growth. VEGFR-1 is also expressed in monocyte/macrophages, and VEGF may regulate the migration of these cells. ${ }^{54}$ VEGFR-1 positive hematopoietic bone marrow progenitor cells may regulate the homing of tumor cells, thus helping to form metastatic lesions. ${ }^{55}$ The blockade of VEGFR-1 may prevent the metastasis of the primary tumors. Pre-clinical experimental data have been obtained using human breast tumor xenografts. An anti-VEGFR-1 monoclonal antibody (mAb), IMC-18F1, reduced tumor cell proliferation. ${ }^{56}$ VEGFR-2 is the major transducer of VEGF signals in endothelial cells, thus constituting the major target for antiangiogenic therapy. IMC-1121 is a VEGFR-2 $\mathrm{mAb}$ that inhibits the VEGF-stimulated proliferation of human endothelial cells. Furthermore, IMC-1121 inhibited leukemia growth in animal models. ${ }^{57} \mathrm{hF} 4-3 \mathrm{C} 5$ is a VEGFR-3 mAb that reacts with lymphatic endothelial cells as well as human umbilical vein endothelial cells. ${ }^{58}$

5) TKI for VEGFR: Sorafenib and sunitinib belong to this category. These agents are discussed later.

6) Downstream targets of VEGFR (Fig. 4): The autophosphorylation of tyrosine residues in VEGFR-2 has been observed. ${ }^{59}$ The phosphorylation of Y1175 leads to the activation of the protein kinase $\mathrm{C}$ (PKC) pathway. This pathway also stimulates the c-Raf-MEKMAP-kinase signal. Y1175 constitutes a binding site for Shb, a signal adaptor for PI3K, suggesting a downstream signal cascade involving the PI3K-Akt pathway. ${ }^{60}$ Phosphorylated Y951 binds to T-cell-spe- 


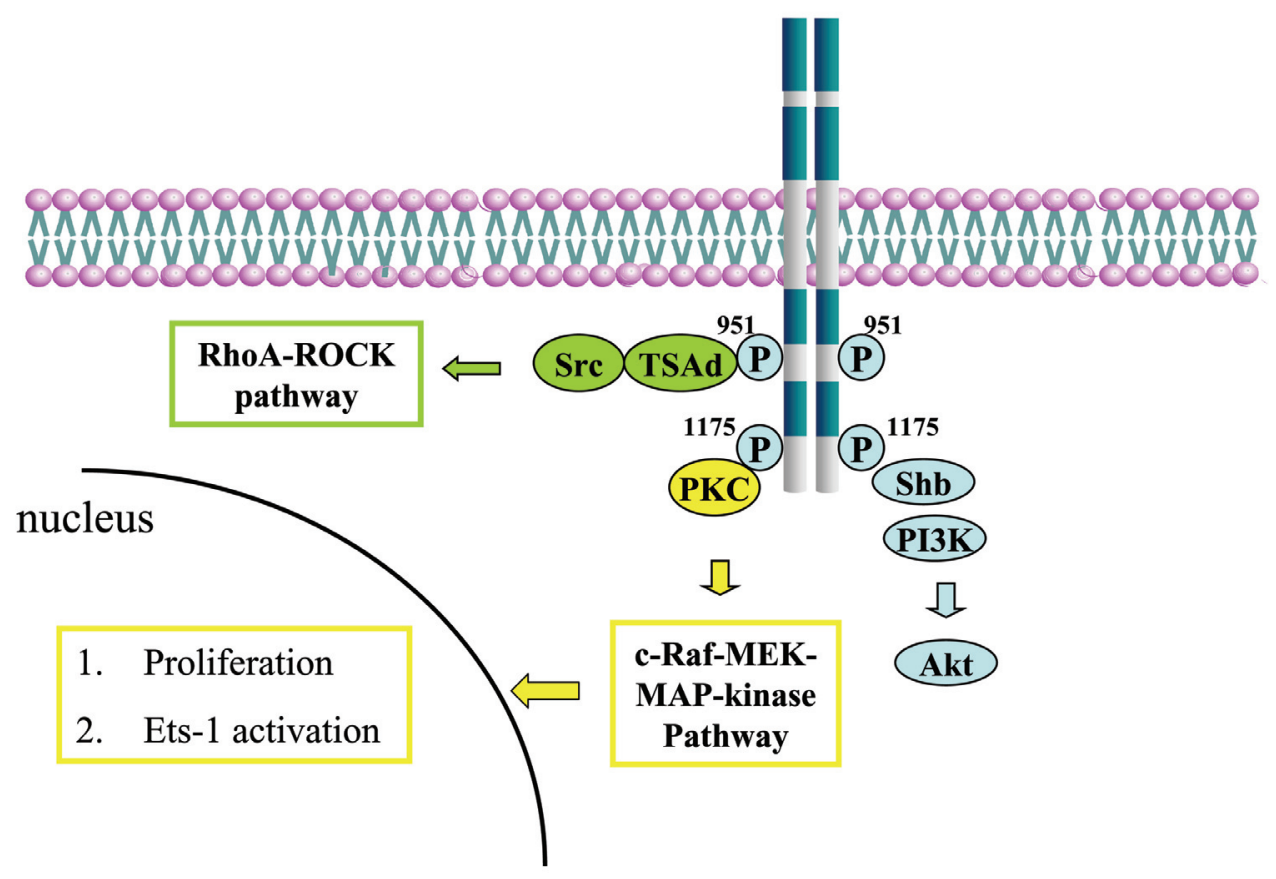

Fig. 4 Signals from VEGF-R. The PI3K-Akt pathway, Raf-MAPK pathway and ROCK pathway are the major pathways involving activated VEGF-R.

cific adapter (TSAd), which is expressed in tumor vessels. TSAd has a Src Homology 2 (SH2) site and associates with Src. Src alters the cell structure to enable cell migration by modulating the actin cytoskeleton through its influence on the RhoA-ROCK pathway. ${ }^{61}$ Inhibitors of these signal transduction pathways might be treatment options for blocking the activity of of VEGF.

Ets-1 is a well-known downstream transcription factor in the VEGF signal cascade. Ets-1 converts endothelial cells to an angiogenic phenotype by inducing the expression of urokinase-type plasminogen activator (uPA), matrix metalloproteinase-1 (MMP-1), MMP-3, MMP-9 and integrin $\beta 3 .{ }^{62}$ Ets- 1 appears to be a key transcription factor for extracellular matrix remodeling in angiogenesis. Indeed, endothelial cells surrounding clear cell RCC were positive for Ets-1. ${ }^{63}$ The specific inhibition of Ets-1 to inhibit angiogenesis may be a potential therapeutic strategy for clear cell RCC.

\section{Anti-angiogenic Agents Currently in Use: Sorafenib and Sunitinib}

Sorafenib is an oral inhibitor of Raf kinase, which is a crucial kinase in ras-MAP kinase signal transduction. Sorafenib is supposed to have an anti-proliferative effect on pancreatic cancers carrying oncogenic ras mutations; however, sorafenib has not shown any anti-tumor effect in pancreatic cancer. Although MAP kinase is constitutively activated in RCC cell lines, ${ }^{64}$ ras mutations in RCC are extremely rare. However, further basic studies have revealed that sorafenib also inhibits receptor tyrosine kinases, including VEGFR2 and VEGFR3. The inhibition of ras-MAP kinases was not associated with any growth-inhibitory effects, ${ }^{65}$ suggesting that sorafenib's underlying mechanism of activity depends on anti-angiogenesis. In a phase II randomized discontinuation trial (RDT), 202 patients were treated with $400 \mathrm{mg}$ of sorafenib twice daily during the run-in period. Seventythree patients exhibited tumor shrinkage of more than $25 \%$. Sixty-five patients with stable disease at $12 \mathrm{wks}$ were randomly assigned to a sorafenib $(\mathrm{n}=32)$ or a placebo group $(n=33)$. The median progression-free survival period from the time of randomization was significantly longer in the sorafenib group than in the placebo group ( 24 wks vs. 6 wks, p = 0.009). Adverse events included hypertension, skin reactions on the hands and feet, and diarrhea. ${ }^{66}$ A subsequent randomized placebocontrolled phase 3 trial in cytokine-refractory patients showed a statistically significant improvement in progression-free survival (PFS) from 2.2 months to 5.5 months $(\mathrm{p}<0.01) .{ }^{67}$ Although the objective response rate was $10 \%, 74 \%$ of the patients experienced disease stabilization, enabling a longer PFS period.

Sunitinib is an oral receptor tyrosine kinase inhibitor with antiangiogenic activity via the targeting of VEGFR-2, PDGFR, and KIT. Two phase 2 studies in cyto- 
kine-refractory RCC patients $(50 \mathrm{mg}$ for 4 wks followed by 2 wks of rest) resulted in response rates of $40 \%$ and $34 \%$ among 63 and 106 patients, respectively. ${ }^{68,69}$ Disease stabilization for more than 3 months was observed in $27 \%$ and $29 \%$ of the patients, respectively. The clinical benefit $(\mathrm{CR}+\mathrm{PR}+\mathrm{SD})$ ratios were $67 \%$ and $63 \%$, respectively. Adverse events included hypertension, skin reactions on the hands and feet, and diarrhea. These adverse events were also observed in the sorafenib trials. In addition, leukopenia and thrombocytopenia were also observed. A subsequent randomized phase 3 trial examined sunitinub versus IFN- $\alpha$ as a first-line therapy for clear cell RCC patients. ${ }^{70}$ In this study, $94 \%$ of the patients had either good or intermediate risk features according to the MSKCC risk model. ${ }^{71}$ The response rate was $31 \%$ versus $6 \%$, with a doubling of the PFS from 5 to 11 months $(\mathrm{p}<0.001)$.

\section{mTOR is Another Target for the Treatment of RCC}

mTOR is a protein that was discovered during studies to clarify the antifungal activity of rapamycin (a macrolide); rapamycin was later shown to have immunosuppressive and anti-cancer activities. mTOR constitutes two complexes designated as mTORC1 and mTORC2. mTORC1 has three components, (mTOR, raptor and mLST8), whereas. mTORC2 has four components, (mTOR, rictor, $\mathrm{mSin} 1$ and $\mathrm{mLST} 8)^{72}$ mTORC1 regulates cell growth, ribosome biogenesis, and autophagy. How rapamycin perturbs mTOR function is not fully understood. mTOR forms a complex with its intracellular receptor, FKBP12, and binds directly to $\mathrm{mTORC} 1$, suppressing the phosphorylation of the substrates S6K1 and 4EBP1. Rapamycin also weakens the interaction between mTOR and raptor. ${ }^{73}$ The TSC1 (tuberous sclerosis1, hamartin)-TSC2 (tuberin) complex acts as a negative regulator. Notably, Akt directly phosphorylates and inhibits the TSC1-TSC-2 complex, eventually activating mTORC1. The PI3K-AKT signal is activated in several types of cancers. Therefore, the link with mTORC1 suggests a targeted therapy for cancer.

Akt is a subfamily of the serine/threonine protein kinases and is thought to play a crucial role in controlling the balance between cell survival and apoptosis. ${ }^{74}$ In various types of human malignant tumors, including colon cancer, ${ }^{75}$ ovarian cancer, ${ }^{76}$ endometrial cancer, ${ }^{77}$ and thyroid cancer, ${ }^{78}$ high frequencies of elevated Akt activation have been demonstrated. We reported that an elevation in Akt activation in RCC was correlated with a higher tumor grade and metastasis, resulting in a poorer patient outcome. ${ }^{79}$ One of the mechanisms underlying elevations in Akt activation has been shown to be the inactivation of the PTEN (phosphatase and tensin homologue deleted on chromosome 10) tumor suppressor gene, which is located on 10q23.3. PTEN is a lipid phos- phatase that dephosphorylates the 3-position of phosphatidylinositol 3,4,5-triphosphate (PIP3), a secondary messenger of phosphatidylinositol 3-kinase (PI3K). ${ }^{80}$ PTEN antagonizes PI3K activity and negatively regulates Akt. We reported that PTEN expression was reduced in RCC and that this reduction was correlated with Akt activation. ${ }^{81}$ These observations suggest that mTORC1 might be a target for the treatment of RCC. Indeed, clinical trials have shown temsirolimus (see below) to be effective against RCC, and the U.S. FDA has approved this agent. However, rapamycin analogues have not shown good anti-tumor effects against tumors that are known to have high Akt activities, such as breast cancer and glioblastoma. ${ }^{82,83}$ Recent in vitro studies have shown that mTORC1 inhibition induced Akt activation, possibly indicating a mechanism of resistance. ${ }^{84,85}$ The inhibition of PI3K signaling has also been reported to block the rapamycin-mediated activation of Akt. ${ }^{86}$ Thus, the combination of an mTOR inhibitor and a PI3K inhibitor may be a plausible strategy for the treatment of rapamycin-resistant tumors.

\section{Temsirolimus}

Temsirolimus is an ester of rapamycin. In a phase 2 study of 111 patients with advanced refractory RCC, the response rate was 7\% and minor responses were observed in $26 \%{ }^{87} \mathrm{~A}$ randomized phase 3 study with three arms was also performed; the $3 \mathrm{arms}$ consisted of IFN- $\alpha$, temsirolimus $(25 \mathrm{mg})$, and IFN- $\alpha+$ temsirolimus (15 $\mathrm{mg}){ }^{88}$ Of note, this study was performed as a first-line therapy and included patients regarded as having a poor risk according to a modified MSKCC risk stratification (multiple organ metastases were added to the five risk factors). The primary endpoint was overall survival (OS). Patients treated with temsirolimus had a median OS of 10.9 months, versus 7.3 months for the IFN- $\alpha$ group $(p=0.007)$ and 8.4 for the combination group (not significant; NS). The response rates in this study were low: $9 \%, 7 \%$, and $11 \%$, respectively. The adverse events were minor, including stomatitis, peripheral edema and rash. Patients should be carefully monitored for interstitial pneumonia and hyperglucosemia. Generally speaking, OS is the ideal study endpoint for evaluating cancer agents. However, the response rate may also be used as a surrogate endpoint to evaluate tumor shrinkage. This phase 3 study typically demonstrated that the response rate does not necessarily reflect OS. Molecular-targeted agents may have cytostatic efficacies that may be better evaluated using PFS or the clinical benefit ratio, rather than the response rate.

\section{Crucial Questions}

Anti-angiogenic agents are likely to be used widely for 
the treatment of RCC. However, several crucial questions remain unanswered. What is the refractory mechanism of RCC for anti-angiogenic agents? How can we identify patients most likely to benefit from moleculartargeted therapy? What is the best administration sequence for these agents? Can combination therapies improve outcomes? Is there any role for immunotherapy? If molecular-targeted agents can be used to improve the immune microenvironment, immunotherapy might be a useful sequential therapy after molecular-targeted therapy. Further basic and clinical studies are needed to answer these questions.

\section{References}

1. Oya M, Murai M:Renal cell carcinoma: relevance of pathology. Curr. Opin. Urol , 2003;13:445-449

2. Lokich J: Spontaneous regression of metastatic renal cancer. Case report and literature review. Am J Clin Oncol 1997; 20:416-418

3. Sobin L H, Wittekind C:TNM classification of Malignant Tumours, $6^{\text {th }}$ ed. Wiley-Liss Publications, New York, 2002;193-195

4. Kaelin WG Jr: The von hippel-lindau tumor suppressor protein: an update. Methods Enzymol 2007; 435: 371-383

5. Shuin T, Kondo K, Torigoe S, Kishida T, Kubota Y, Hosaka M, et $a l$ : Frequent somatic mutations and loss of heterozygosity of the von Hippel-Lindau tumor suppressor gene in primary human renal cell carcinomas. Cancer Res 1994; 54: 2852-2855

6. Herman J G, Latif F: Silencing of the VHL tumor-suppressor gene by DNA methylation in renal carcinoma. Proc Natl Acad Sci USA 1994; 91: 9700-9704

7. Kamura T, Koepp DM, Conrad MN, Skowyra D, Moreland RJ, Iliopoulos $\mathrm{O}$, et al.: Rbx1, a component of the VHL tumor suppressor complex and SCF ubiquitin ligase. Science 1999; 284: 657661

8. Maxwell PH, Wiesener MS, Chang GW, Clifford SC, Vaux EC, Cockman ME, et al.: The tumor suppressor protein VHL targets hypoxia-inducible factors for oxygen-dependent proteolysis. Nature 1999; 399: 271-275

9. Kaelin WG Jr: The von Hippel-Lindau gene, kidney cancer, and oxygen sensing. J Am Soc Nephrol 2003; 14: 2703-2711

10. Igarashi H, Esumi M, Ishida H, Okada K: Vascular endothelial growth factor overexpression is correlated with von Hippel-Lindau tumor suppressor gene inactivation in patients with sporadic renal cell carcinoma. Cancer 2002; 95: 47-53

11. Turner KJ, Moore JW, Jones A, Taylor CF, Cuthbert-Heavens D, Han $\mathrm{C}$, et al.: Expression of hypoxia-inducible factors in human renal cancer: relationship to angiogenesis and to the von HippelLindau gene mutation. Cancer Res 2002; 62: 2957-2961

12. Bui MHT, Seligson D, Han K, Pantuck AJ, Dorey FJ, Huang Y, et al.: Carbonic anhydrase IX is an independent predictor of survival in advanced renal clear cell carcinoma: implications for prognosis and therapy. Clinical Cancer Res 2003 ; 9(2):802-811

13. Leibovich BC, Sheinin Y, Lohse CM, Thompson RH, Cheville JC, Zavada J, et al.: Carbonic anhydrase IX is not an independent predictor of outcome for patients with clear cell renal cell carcinoma. J Clin Oncol 2007; 30: 4757-4764

14. Kondo K, Klco J, Nakamura E, Lechpammer M, Kaelin WG Jr: Inhibition of HIF is necessary for tumor suppression by the von Hippel-Lindau protein. Cancer Cell 2002;1:237-246

15. Mranchie JK, Vasseli JR, Riss J, Bonifacio JS, Linehan WM, Klausner RD: The contribution of VHL substrate binding and HIF $1-\alpha$ to the phenotype of VHL loss in renal cell carcinoma. Cancer Cell 2002; 1:247-255

16. Esteban MA, Harten SK, Tran MG, Maxwell PH: Formation of primary cilia in the renal epithelium is regulated by the von Hippel-Lindau tumor suppressor protein. J Am Soc Nephrol 2006; 17: $1801-1806$

17. Lutz M, Burk RD: Primary cilium formation requires von HippelLindau gene function in renal derived cells. Cancer Res 2006; 66: 6903-6907

18. Shermer B, Ghenoiu c, Bartram M, Müller RU, Kotsis F, Höhne $\mathrm{M}$, et al:: The von Hippel-Lindau tumor suppressor protein controls ciliogenesis by orienting microtubule growth. J Cell Biol 2006; 175:547-554

19. Pazour GJ: Intraflagellar transport and clia-dependent renal disease: the ciliary hypothesis of polycystic kidney disease. J Am Soc Nephrol 2004; 15: 2528-2536

20. Hergovich A, Lisztwan J, Barry R, Ballschmieter P, Krek W: Regulation of microtubule stability by the von Hippel-Lindau tumor suppressor protein pVHL. Nat Cell Biol 2003; 5:64-70

21. Kuehn EW, Walz Z, Benzing T: von Hippel-Lindau: a tumor suppressor links microtubules to ciliogenesis and cancer development. Cancer Res 2007; 67: 4537-4540

22. Quarmby LM, Parker JD: Cilia and the cell cycle? J Cell Biol 2005; 169:707-710

23. O'connell MJ, Krien MJ, Hunter T: Never say never. The NIMArelated protein kinases in mitotic control. Trends Cell Biol 2003; 13:221-228

24. Ito K, Asano T, Yoshii H, Satoh A, Sumitomo M, Hayakawa M: Impact of thrombocytosis and C-reactive protein elevation on the prognosis for patients with renal cell carcinoma. Int J Urol 2006; 13:1365-1370

25. Karakiewicz PI, Hutterer GC, Trinh Q-D, Jeldres C, Perrotte P, Gallina A, et al.: C-reactive protein is an informative predictor of renal cell carcinoma-specific mortality. Cancer 2007; 110:12411247

26. Tsukamoto T, Kumamoto Y, Miyao N, Masumori N, Takahashi A, and Yanase M: Interleukin-6 in renal cell carcinoma. J Urol: 148: $1778-1781$

27. Blay JK, Negrier S, Combaret V, Attali S, Goillot E, Merrouche Y, et al.: Serum level of interleukin 6 as a prognosis factor in metastatic renal cell carcinoma. Cancer Res; 1992; 52: 3317-3322

28. Miki S, Iwano M, Miki Y, Yamamoto M, Tang B, Yokokawa K, Sonoda T, Hirano T and Kishimoto T: FEBS Lett: 250: 607-610

29. Negrier S, Perol D, Menetrier-Caux C, Escudier B, Pallardy M, Ravaud A, et al: Interleukin-6, interleukin-10, and vascular endothelial growth factor in metastatic renal cell carcinoma: prognostic value of Interleukin-6. J Clin Oncol 2004; 22:2371-2378

30. Yoshida N, Ikemoto S, Narita K, Sugimura K, Wada S, Yasumoto $\mathrm{R}$, et al: Interluekin-6, tumor necrosis factor alpha and interleukin-1 beta in patients with renal cell carcinoma. Br J Cancer 2002; 86: $1396-1400$

31. Oya M, Takayanagi A, Horiguchi A, Mizuno M, Ohtsubo, M, Marumo, $\mathrm{K}$, et al.: Increased nuclear factor- $\mathrm{\kappa B}$ activation is related to the tumor development of renal cell carcinoma. Carcinogenesis $2003 ; \mathbf{2 4}, 377-384$

32. An J and Rettg MB: Mechanism of von Hippel-Lindau proteinmediated suppression of nuclear factor kappa B activity. Mol Cell Biol 2005; 25:7546-7556

33. Yang H, Minamishima YJ, Yan Q, Schlisio S, Ebert BL, Zhang X, Zhang L, Kim WY, Olumi AF and WG Kaelin: pVHL acts as an adaptor to promote the inhibitory phosphorylation of the NF- $\kappa B$ agonist Card9 by CK2. Mol Cell 2007; 28: $15-27$

34. Oya M, Ohtsubo M, Takayanagi A, Tachibana M, Shimizu N, Murai $\mathrm{M}$ : Constitutive activation of nuclear factor- $\kappa \mathrm{B}$ prevents TRAIL-induced apoptosis in renal cancer cells. Oncogene 2001; 20: $3888-3896$

35. An J, Sun Y, Fisher M, Rettig MB: Maximal apoptosis of renal cell carcinoma by the proteasome inhibitor bortezomib is nuclear factor- $\kappa B$ dependent. Mol Cancer Ther 2004; 3: 727-736

36. Horiguchi A, Oya M, Shimada T, Uchida A, Marumo K, Murai M: 
Activation of signal transducer and activator of transcription 3 in renal cell carcinoma: a study of incidence and its association with pathological features and clinical outcome. J. Urol 2002; 168: 762 $-765$

37. Oya M, Horiguchi A, Mizuno M, Marumo K, Murai M: Increased activation of CCAAT/enhancer binding protein- $\beta$ correlates with the invasiveness of renal cell carcinoma. Clin. Cancer Res 2003; 9: $1021-1027$

38. Duluc D, Delneste Y, Tan F, Moles M-P, Grimaud L, Lenoir J, et al.: Tumor-associated leukemia inhibitory factor and IL-6 skew monocyte differentiation into tumor-associated macrophage-like cells. Blood 2007; 110: 4319-4330

39. Garcia JA, Rini BI: Recent progress in the management of advanced renal cell carcinoma. CA Cancer J Clin 2007;57:112-125

40. Gouttefangeas C, Stenzl A, Stevanovic S, Rammensee H-S: Immunotherapy of renal cell carcinoma. Cancer Immunol Immunother 2007; 56:117-128

41. Kitamura H, Honma I, Torigoe T, Asanuma H, Sato H, Tsukamoto $\mathrm{T}$ : Down-regulation of HLA classI antigen is an independent prognostic factor for clear cell renal cell carcinoma. J Urol 2007; 177: $1269-1272$

42. Kronfeld K, Abken H, Seliger B: B7-1 and B7-2 act differentially in the induction of a $\mathrm{T}$ cell response: their impact for a HLAmatched anti-tumor immunotherapy. Int J Cancer 2005; 117: 794 $-799$

43. Dong H, Strome SE, Salomao DR, Tamura H, Hirano F, Flies DB, et al.: Tumor-associated B7-1 promotes T-cell apoptosis: a potential mechanism of immune evasion. Nat Med 2002; 8: 793-800

44. Thompson RH, Kunz SM, Leibovich BC, Dong H, Lohse CM, Webster WS, et al: Tumor B7-H1 is associated with poor prognosis in renal cell carcinoma patients with long-term follow-up. Cancer Res 2006; 66: 3381-3385

45. Thompson RH, Dong H, Lohse CM, Leibovich BC, Blute ML, Cheville JC, et al:: PD-1 is expressed by tumor-infiltrating immune cells and is associated with poor outcome for patients with renal cell carcinoma. Clin Cancer Res 2007; 13:1757-1761

46. Cesana GC, DeRaffele G, Cohen S, et al: Characterization of $\mathrm{CD} 4+\mathrm{CD} 25+$ regulatory $\mathrm{T}$ cells in patients treated with high-dose interleukin-2 for metastatic melanoma or renal cell carcinoma. J Clin Oncol 2006; 24: 1169-1177

47. Zea AH, Rodriguez PC, Atkins MB, Hernandez C, Signoretti S, Zabaleta J, et al.: Arginase-producing myeloid suppressor cells in renal cell carcinoma patients: a mechanism of tumor evasion. Cancer Res 2005; 65: 3044-3048

48. Shinojima T, Oya M, Takayanagi A, Mizuno R, Shimizu N, Murai M: Renal cancer cells lacking hypoxia inducible factor (HIF) $1-\alpha$ expression maintain vascular endothelial growth factor expression through HIF 2- $\alpha$. Carcinogenesis 2007; 28: 529-536

49. Tan C, de Noronha RG, Roecker AJ, Pyrzynska B, Khwaja F, Zhang Z, Zhang H, et al.: Identification of a novel small-molecule inhibitor of the hypoxia-inducible factor 1 pathway. Cancer Res 2005; 65:605-612

50. Creighton-Gutterige M, Cardellina JH $2^{\text {nd }}$, Stephen AG, Rapisarda A, Uranchimeg B, Hite K, et al.: Cell type-specific, topoisomerase II-dependent inhibition of hypoxia-inducible factor-1alpha protein accumulation by NSC 644221. Clin Cancer Res 2007; 13:10101018

51. Hudson CC, Liu M, Chiang GG, Otterness DM, Loomis DC, Kaper F, et al.: Regulation of hypoxia-inducible factor 1 alpha expression and function by the mammalian target of rapamycin. Mol Cell Biol 2002; 22: 7004-7014

52. Yang JC, Haworth L, Sherry RM, Hwu P, Schwartzentruber DJ, Topalian SL, et al: : A randomized trial of bevacizumab, an antivascular endothelial growth factor antibody, for metastatic renal cancer. N Engl J Med 2003; 349:427-434

53. Riely GJ, Miller VA: Vascular endothelial growth factor trap in non-small cell lung cancer. Clin Cancer Res 2007; 13 :4623s -
$4627 \mathrm{~s}$

54. Sawano A, Iwai S, Sakurai Y, Ito M, Shirata K, Nakahata T, et al.: Flt-1, vascular endothelial growth factor receptor 1. is a novel cell surface marker for the lineage og monocyte-macrophages in humans. Blood 2001; 97: 785-791

55. Kaplan RN, Riba RD, Zacharoulis S, Bramley AH, Vincent L, Costa C, et al.: VEGFR1-positive haematopoietic bone marrow progenitors initiate the pre-metastatic Nature $2005 ; \mathbf{4 3 8}, 820-827$

56. WuY, Zhong Z, Huber J, Bassi R, Finnerty B, Corcoran E, et al.: Anti-vascular endothelial growth factor receptor-1 antagonist antibody as a therapeutic agent for cancer. Clin Cancer Res 2006; 12: $6573-6584$

57. Zhu Z, Hattori K, Zhang H, Jimenez X, Ludwig DL, Dias S, et $a l$ : Inhibition of human leukemia in an animal model with human antibodies directed against vascular endothelial growth factor receptor 2 . Correlation between antibody affinity and biological activity. Leukemia 2003;17: 604-611

58. Persaud K, Tille J-C, Liu M, Zhu Z, Jimenez X, Pereira DS, et al.: Involvement of the VEGF receptor 3 in tubular morphogenesis demonstrated with a human anti-human VEGFR-3 monoclonal antibody that recognizes receptor activation by VEGF-C. J Cell Sci 2004; 117: 2745-2756

59. Matsumoto T, Bohman S, Dixelius J, Berge T, Dimberg A, Magnusson $\mathrm{P}$, et al: VEGF receptor-2 Y951 signaling and a role for the adapter molecule TSAd in tumor angiogenesis. EMBO J 2005; 24: $2342-2353$

60. Holmqvist K, Cross MJ, Rolny R, Hagerkvist N, Rahimi T, Matsumoto L, et al.: The adaptor protein shb binds to tyrosine 1175 in vascular endothelial growth factor (VEGF) receptor-2 and regulates VEGF-dependent cellular migration. J Biol Chem 2004; 279:22267-22275

61. Frame MC: Newest findings on the oldest oncogene; how activated $\operatorname{src}$ does it. J Cell Sci 2004; 117, 989-998

62. Sato Y, Kanno S, Oda N, Abe M, Ito M, Shitata K, et al.: Properties of two VEGF receptors, Flt-1 and KDR, in signal transduction. Ann NY Acad Sci 2000; 902: 201-205

63. Mikami S, Oya M, Mizuno R, Murai M, Mukai M, Okada Y: Expression of Ets-1 in human clear cell renal cell carcinomas: implications for angiogenesis. Cancer Sci 2006; 97: 875-882

64. Oka H, Chatani Y, Hoshino R, Ogawa O, Kakehi Y, Terachi T, et al.: Constitutive activation of mitogen-activated protein (MAP) kinases in human renal cell carcinoma. Cancer Res 1995; 55: $4182-4187$

65. Horiguchi A, Oya M, Marumo K, Murai M: STAT3, but not ERKs mediates IL-6-induced proliferation of renal cancer cells, ACHN and 769P. Kidney Int 2002; 61: 926-938

66. Ratani MJ, Eisen T, Stadler WM, Flaherty KT, Kaye SB, Rosner GL, et al.: Phase II placebo-controlled randomized discontinuation trial of sorafenib in patients with metastatic renal cell carcinoma. J Clin Oncol 2006; 24:2505-2512

67. Escudier B, Eisen T, Stadler WM: Szczylik C, Oudard S, Siebels $\mathrm{M}$, et al.: Sorafenib in advanced clear-cell renal-cell carcinoma. N Engl J Med 2007; 356: $125-134$

68. Motzer RJ, Michawlson MD, Redman BG, Hudes GR, Wilding G, Figlin RA, et al.: Activity of SU11248, a multitargeted inhibitor of vascular endothelial growth factor receptor and plateret-derived growth factor receptor, in patients with metastatic renal cell carcinoma. J Clin Oncol 2006; 24 :16-24

69. Motzer RJ, Rini BI, Bukowsky RM, Curti BD, George DJ, Hudes GR, et al.: Sunitinib in patients with metastatic renal cell carcinoma. JAMA 2006; 295: 2516-2524

70. Motzer RJ, Hutson TE, Pharm D, Tomczak P, Michawlson MD, Bukowsky RM, et al: Sunitinib versus Interferon alfa in metastatic renal-cell carcinoma. N Engl J Med 2007; 356: 115-124

71. Motzer RJ, Bacik J, Murphy BA, Russo P, Mazumdar M: Interferon-alfa as a comparative treatment for clinical trials of new therapies against advanced renal cell carcinoma. J Clin Oncol 2002; 20 
:289-296

72. Sabatini DM: mTOR and cancer: insights into a complex relationship. Nature Rev Cancer 2006; 6: 729-734

73. Kim DH, Sarbassov DD, Ali SM, King JE, Latek RR, ErdjumentBromage $\mathrm{H}$, et al:: mTOR interacts with Raptor to form a nutrientsensitive complex that signals to the cell growth machinery. Cell 2002; 110: $163-175$

74. Franke TF, Kaplan DR, Cantley LC: PI3K: downstream AKTion blocks apoptosis. Cell 1997; 88: 435-437

75. Itoh N, Semba $S$, Ito $M$, Takeda $H$, Kawata S, Yamakawa M: Phosphorylation of Akt/PKB is required for suppression of cancer cell apoptosis and tumor progression in human colorectal carcinoma. Cancer 2002; 94: 3127-3134

76. Kurose K, Zhou XP, Araki T, Cannistra SA, Maher ER, Eng C: Frequent loss of PTEN expression is linked to elevated phosphorylated Akt levels, but not associated with p27 and cyclin D1 expression, in primary epithelial ovarian carcinomas. Am J Pathol 2001; 158: 2097-2106

77. Kanamori Y, Kigawa J, Itamochi H, Shimada M, Takahashi M, Kamazawa S, et al.: Correlation between loss of PTEN expression and Akt phosphorylation in endometrial carcinoma. Clin Cancer Res 2001; 7: 892-895

78. Ringel MD, Hayre N, Saito J, Saunier B, Schuppert F, Burch H, et al.: Overexpression and overactivation of Akt in thyroid carcinoma. Cancer Res 2001; 61: 6105-6111

79. Horiguchi A, Oya M, Uchida A, Marumo K, Murai M: Elevated Akt activation and its impact on clinicopathological features of renal cell carcinoma. J Urol 2003; 169: 710-713

80. Maehama T, Dixon JE. The tumor suppressor, PTEN/MMAC1, dephosphorylates the lipid second messenger, phosphatidylinositol 3,4,5-trisphosphate. J Biol Chem 1998; 273: 13375-13378
81. Hara S, Oya M, Mizuno R, Horiguchi A, Marumo K, Murai M: Akt activation in renal cell carcinoma: contribution of a decreased PTEN expression and the induction of apoptosis by an Akt inhibitor. Ann. Oncol 2005; 16: 928-933

82. Chan S, Scheulen ME, Johnston S, Mross K, Cardoso F, Dittrich C, et al.: Phase II study of temsirolimus(CCI-779), a novel inhibitor of mTOR, in heavily pretreated patients with locally advanced or metastatic breast cancer. J Clin Oncol 2005; 23: 5314-5322

83. Galanis EJ, Buckner JC, Maurer MJ, Kreisberg JI, Ballman K, Boni J, et al.: Phase II study of temsirolimus(CCI-779), a novel inhibitor of mTOR, in recurrent glioblastoma multiforme: a North central Cancer Treatment Group Study. J Clin Oncol 2005; 23: $5294-5304$

84. Sun SY, Rosenberg LM, Wang X, Zhou Z, Yue P, Fu H, et al.: Activation of Akt and elf4E survival pathways by rapamycin inhibition. Cancer Res 2005; 65: 7052-7058

85. O'Reilly KE, Rojo F, She QB, Solit D, Mills GB, Smith D, et al.: mTOR inhibition induces upstream receptor tyrosine kinase signaling and activates Akt. Cancer Res 2006; 66: 1500-1508

86. Fan Q-W, Knight ZA, Goldenberg DD, Yu W, Mostov KE, Stokoe $\mathrm{D}$, et al.: a dual PI3 kinase/Mtor inhibitor reveals efficacy in glioma. Cancer Cell 2006; 9: 341-349

87. Atkins MB, Hidalgo M, Stadler WM, Logan TF, Dutcher JP, Hudes GR, et al.: Randomized phase II study of multiple dose levels of CCI-779, a novel mTOR kinase inhibitor, in patients with advanced refractory renal cell carcinoma. J Clin Oncol 2004; 22: 909-918

88. Hudes G, Carducci M, Tomczak P, Dutcher J, Figlin R, Kapoor A, et al.: Temsirolimus, Interferon alfa, or both for advanced renalcell carcinoma. N Engl J Med 2007; 356: 2271-2281 